\title{
Repurposing clinical drugs is a promising strategy to discover drugs against Zika virus infection
}

\author{
Weibao Song*, Hongjuan Zhang*, Yu Zhang, Rui Li, Yanxing Han, Yuan Lin (ه), Jiandong Jiang (ه) \\ State Key Laboratory of Bioactive Substances and Function of Natural Medicine, Institute of Materia Medica, Chinese Academy of Medical \\ Sciences and Peking Union Medical College, Beijing 100050, China
}

(C) The Author(s) 2020. This article is published with open access at link.springer.com and journal.hep.com.cn

\begin{abstract}
Zika virus (ZIKV) is an emerging pathogen associated with neurological complications, such as Guillain-Barré syndrome in adults and microcephaly in fetuses and newborns. This mosquito-borne flavivirus causes important social and sanitary problems owing to its rapid dissemination. However, the development of antivirals against ZIKV is lagging. Although various strategies have been used to study anti-ZIKV agents, approved drugs or vaccines for the treatment (or prevention) of ZIKV infections are currently unavailable. Repurposing clinically approved drugs could be an effective approach to quickly respond to an emergency outbreak of ZIKV infections. The well-established safety profiles and optimal dosage of these clinically approved drugs could provide an economical, safe, and efficacious approach to address ZIKV infections. This review focuses on the recent research and development of agents against ZIKV infection by repurposing clinical drugs. Their characteristics, targets, and potential use in anti-ZIKV therapy are presented. This review provides an update and some successful strategies in the search for anti-ZIKV agents are given.
\end{abstract}

Keywords Zika virus; clinical drugs; ZIKV inhibitors; antivirals; repurposing

\section{Introduction}

Zika virus (ZIKV) of the genus Flavivirus is responsible for large disease outbreaks attributed to transmission by mosquitoes [1]. ZIKV infection may sometimes lead to severe neurological complications, including microcephaly in fetuses and newborns and a remarkable increase in the number of Guillain-Barré syndrome cases [2,3]. Owing to its volatile epidemics and teratogenic effect, the World Health Organization declared ZIKV as a Public Health Emergency of International Concern in 2016 [4].

Similar to other flaviviruses, ZIKV is a single-stranded positive-sense RNA virus approximately $10 \mathrm{~kb}$ in length that encodes a polyprotein [5]. The polyprotein is cleaved into three structural proteins, namely, capsid (C), premembrane (prM), and envelope (E) and seven nonstructural (NS) proteins (NS1, NS2A, NS2B, NS3, NS4A, NS4B, and NS5), which are involved in viral genome replication and virulence [6]. Among these proteins, only

Received June 24, 2020; accepted October 14, 2020

Correspondence: Yuan Lin, linyuan@imm.ac.cn;

Jiandong Jiang, jiang.jdong@163.com

${ }^{*}$ These authors contributed equally to this work.
NS3 and NS5 have enzymatic activities [7]. NS3 possesses serine protease, RNA helicase, RNA triphosphate, and nucleoside triphosphate enzymatic activities [8]. Along with NS2B, NS3 protease is responsible for the cleavage and posttranslational modification of the virus polyprotein [9]. NS5 consists of two domains: methyltransferase (MTase) at the N-terminal, which is responsible for viral RNA cap methylation; and RNA-dependent RNA polymerase (RdRp) at the C-terminal, which is required for viral RNA synthesis [10]. Furthermore, the crystal structures of NS2B/NS3 and NS5 proteins have been resolved [9-12]. As targeting viral enzymes is a proven antiviral approach, evidenced by clinically used antihepatitis $\mathrm{C}$ virus (HCV) and anti-human immunodeficiency virus (HIV) drugs, NS2B/NS3 and NS5 are the main drug targets for anti-ZIKV drug discovery [13]. An overview of ZIKV replication in infected cells is presented in Fig. 1, which describes the important drug targets that can be inhibited by the anti-ZIKV agent.

The general strategies used to search for inhibitors against ZIKV currently include viral protein-based screening $[14,15]$, viral replication-based phenotypic screening $[16,17]$, and repurposing of clinically approved drugs $[18,19]$. Although these strategies have been considered for the identification of anti-ZIKV agents, no specifically 


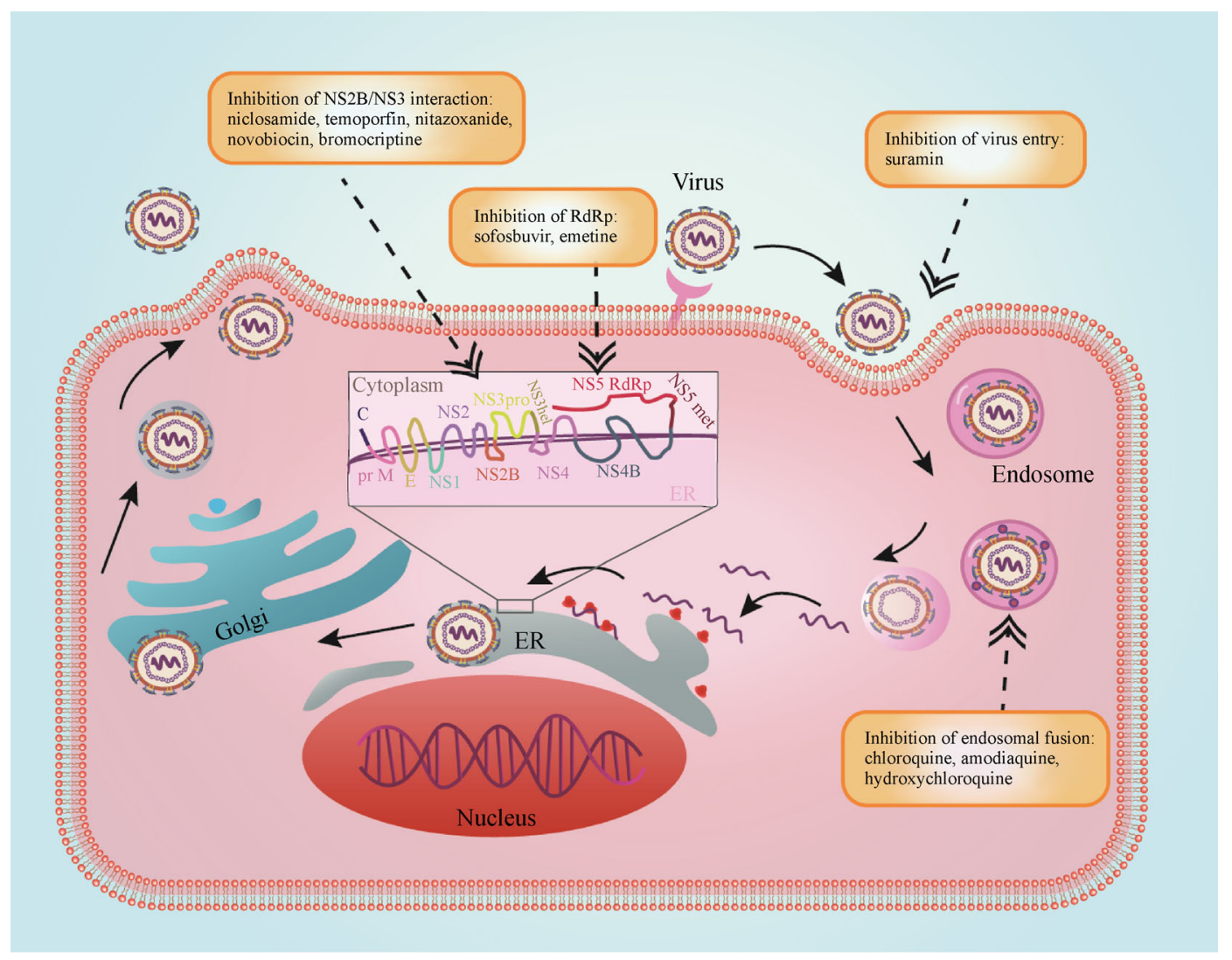

Fig. 1 Overview of ZIKV replication in the infected cells and the important drug targets that can be inhibited by anti-ZIKV agents discussed in this review.

approved drugs or vaccines are currently available to prevent or treat ZIKV infections. Only a few vaccine candidates and antiviral molecules have progressed to phase I and phase II clinical trials [20,21]. Therefore, repurposing existing drugs is a rapid strategy, which has the advantages of cost-saving and speed in identifying antiZIKV agents.

Drug repurposing is defined as "studying drugs that are already approved to treat one disease or condition to assess if they are safe and effective for treating other diseases" [22]. It focuses on US Food and Drug Administration (FDA)-approved drugs, as these drugs have details on potential toxicity, formulation, and pharmacology and drug-like molecules with potential activity [23]. This strategy will address most of the costs and time-consuming hurdles that accompany the drug development process [24]. This approach offers significant achievements to quickly determine ZIKV inhibitors [25,26]. Chloroquine, a well-known antimalarial compound synthesized in 1934, was found to target ZIKV [27,28]. Additionally, sofosbuvir and temoporfin were identified to possess anti-ZIKV activities $[29,30]$. Researchers often use various methods for drug repurposing, including in silico, biological, and experimental approaches. In silico drug repurposing merges and analyzes information regarding drug-disease relationships based on various public databases and information from research, reports, and clinical trials $[31,32]$. Biological approaches have been developed to target multi-factorial complex diseases through systems and network biology [33]. Experimental approaches include the screening of targets, cell assays, animal models, and clinical aspects [34,35]. However, drug repurposing has several disadvantages. Considering the affinity and selectivity for the given primary target, the potency values for novel targets of repurposed drugs are likely to be lower than those observed for the primary target [36]. Conversely, drug repurposing only reduces but does not eliminate the risk of compound development. Therefore, companies need to balance the risks of having a second-in-class drug with lower potency that is not linked to a certain indication.

In this review, we focus on clinically approved drugs that have been evaluated in clinical trials, preclinical studies, animal models, or in vitro anti-ZIKV tests (Table 1).

\section{Inhibitors of RdRp}

$\mathrm{RdRp}$ is the most conserved protein component that plays 


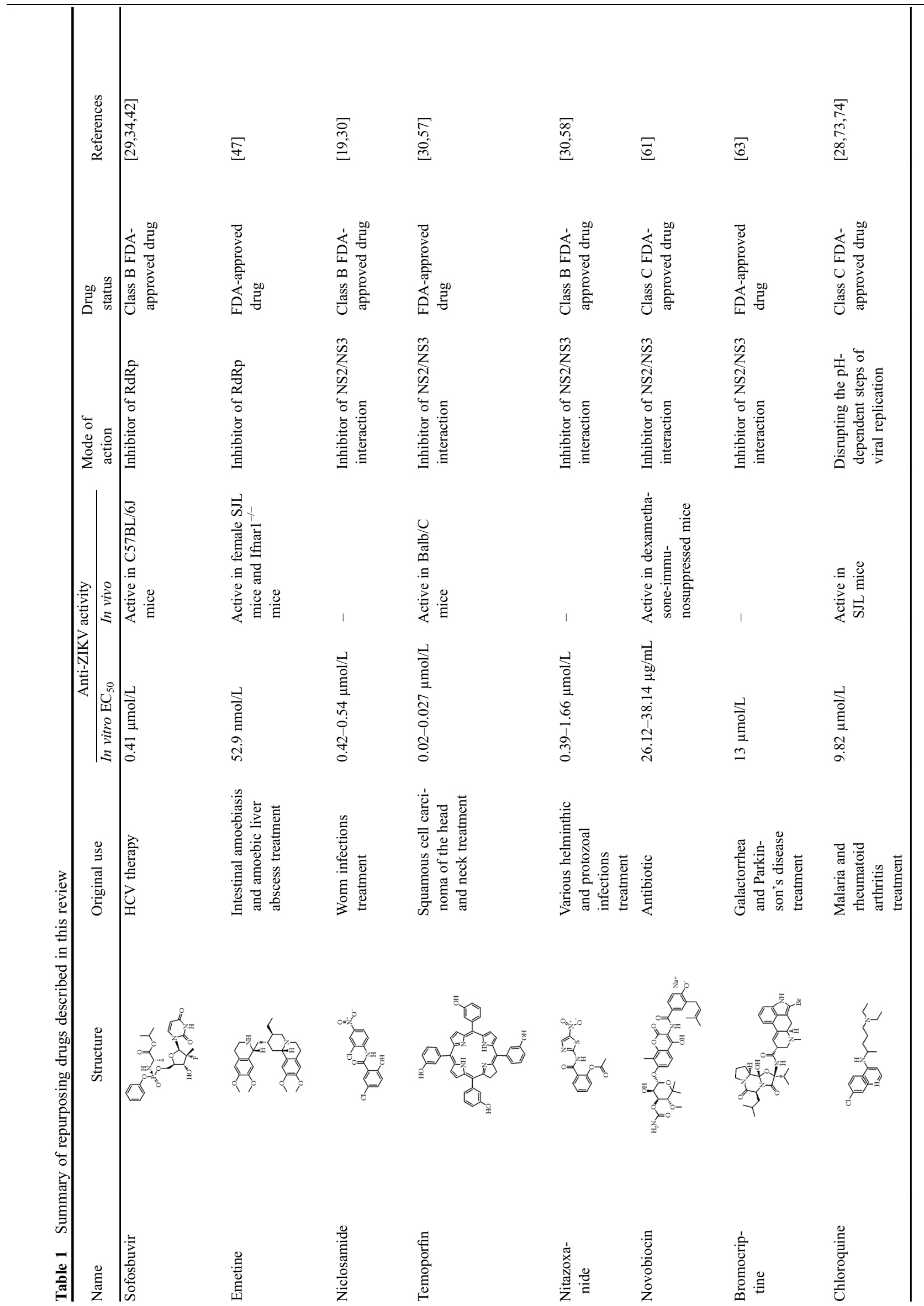




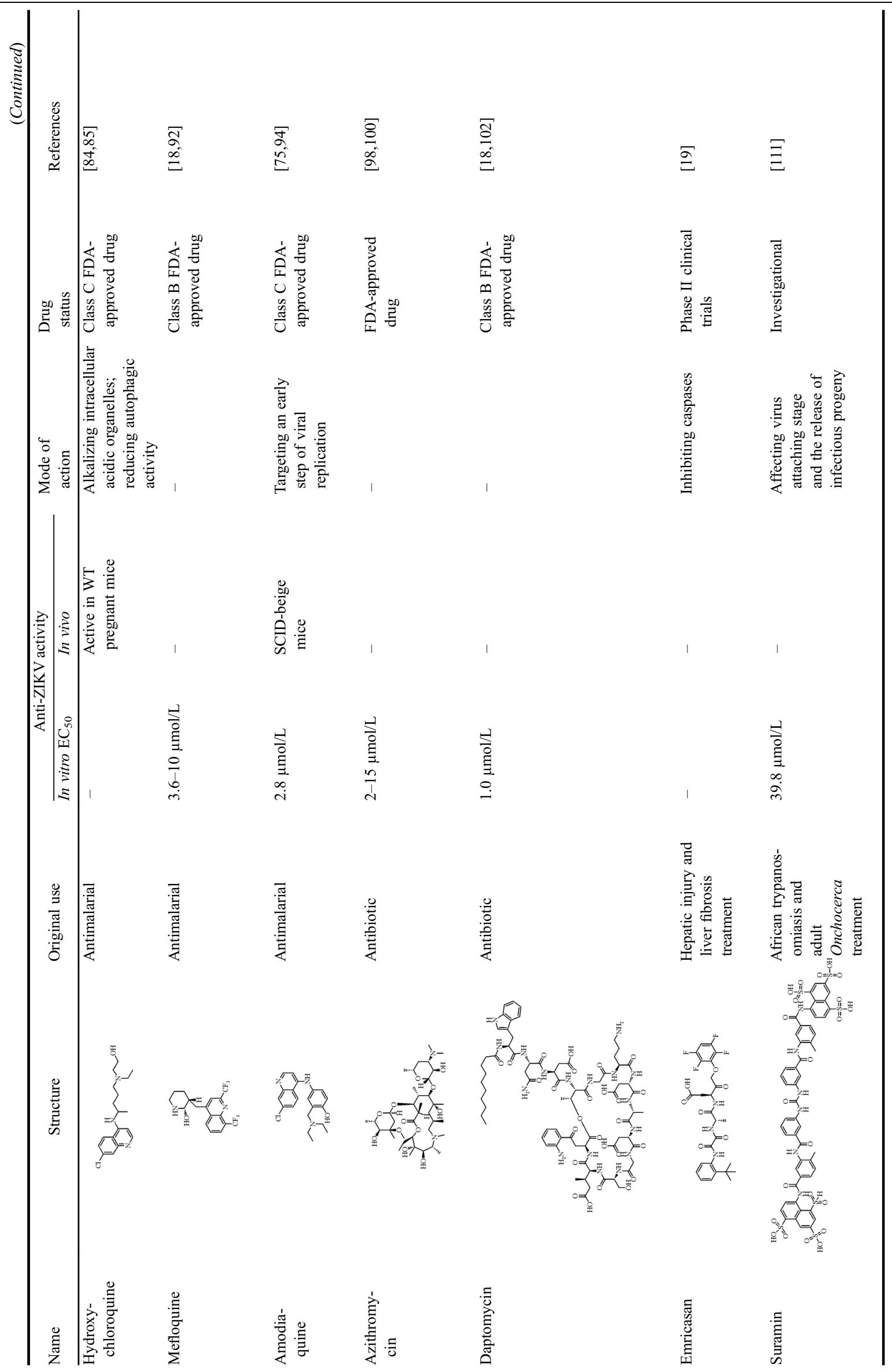


an essential role in viral replication. It is considered a promising target for anti-ZIKV drugs.

Sofosbuvir is a successful drug targeting $\mathrm{RdRp}$ that is used for HCV therapy [37,38]. It is a uridine nucleotide prodrug that is triphosphorylated intracellularly and can be metabolized to the active 5-triphosphate form, 2-deoxy-2$\alpha$-fluoro-2- $\beta$-C-methyluridine-5-monophosphate (PSI7409), in the liver [39,40]. Sofosbuvir is a potent inhibitor of HCV RdRp [41]. Considering its low side effects, good oral administration, and tolerance due to its high potency, sofosbuvir has attracted an increasing amount of attention for development as a direct-acting antiviral drug [38]. Sofosbuvir reportedly inhibited ZIKV replication in Huh-7 cells, with an $\mathrm{EC}_{50}$ (half-maximal effective concentration) of $0.41 \mu \mathrm{mol} / \mathrm{L}[12,29,34,42]$. However, sofosbuvir showed no inhibitory effect on ZIKV replication in Vero and A549 cells. This finding might be correlated with different intracellular concentrations of the active triphosphate metabolite of sofosbuvir, which was 11-342 times higher in Huh-7 cells than in Vero and A549 cells [42]. Sacramento et al. reported that sofosbuvir triphosphate inhibited ZIKV RdRp activity, with a half maximal inhibitory concentration $\left(\mathrm{IC}_{50}\right)$ of $0.38-7.3 \mu \mathrm{mol} / \mathrm{L}$ $[29,43]$. Furthermore, sofosbuvir might increase A-to-G mutations in the viral genome, which is due to anti-ZIKV activity [29]. However, the mutation at S604T of ZIKV RdRp could confer resistance to sofosbuvir [43]. Sofosbuvir protected mice against ZIKV infection and increased survival rates [34]. Sofosbuvir is a class B FDA-approved drug, which implies that it presents no risk to animal fetus. Sofosbuvir's antiviral activity in human neural progenitors and brain organoids demonstrated that it might be a promising drug for clinical ZIKV therapy $[12,29]$.

Emetine, an antiprotozoal agent, is used for intestinal amebiasis and amoebic liver abscess treatment [44-46]. Yang et al. observed that emetine possessed anti-ZIKV activity in HEK293 cells, with an $\mathrm{EC}_{50}$ of $52.9 \mathrm{nmol} / \mathrm{L}$ in vitro, and reduced levels of ZIKV in both female SJL mice and Ifnar $1^{-/}$mice [47]. Emetine is a non-nucleoside compound that directly inhibited ZIKV NS5 RdRp activity, with an $\mathrm{IC}_{50}$ of $121 \mathrm{nmol} / \mathrm{L}$. Moreover, emetine inhibited viral entry by inhibiting lysosome activity [47]. However, emetine has demonstrated potential toxicity toward the fetus, indicating that its use should be avoided during pregnancy [35]. In addition, 10-undecenoic acid zinc salt (UA) was another non-nucleoside drug that inhibits ZIKV replication by targeting RdRp [48]. UA is commonly used in clinics to treat fungal infections [49]. The anti-ZIKV activity of emetine and UA is currently at the in vitro stage. The safety of emetine and UA for pregnancy and newborns needs further evaluation.

Some nucleoside analogs have presented good inhibitory effects on ZIKV by targeting RdRp, including BCX4430, NITD008, and 7-deaza-2'-C-methyladenosine
(7DMA). BCX4430 inhibited ZIKV replication with an $\mathrm{EC}_{50}$ of $3.8-11.7 \mu \mathrm{g} / \mathrm{mL}$ in vitro and showed protective effects on the AG129 mouse model with ZIKV infection [50]. BCX 4430 is currently in phase I clinical trial to evaluate its safety, tolerability, and pharmacokinetics $[25,50]$. NITD008 and 7DMA exhibited antiviral activity against ZIKV in vitro in the micromolar and submicromolar ranges [25]. However, both 7DMA and NITD008 failed during clinical trials [51].

\section{NS2B/NS3 protease inhibitor}

The protease complex, NS2B/NS3, plays an important role in the hydrolysis of ZIKV polyproteins into functional formats. The cleaved proteins, thus function in the process of viral propagation and maturation. In the NS2B/NS3 complex, the partial residues (residues 49-95) in NS2B could help NS3 cleave vital polyproteins more effectively [52-54]. The unlinked construct of NS2B/NS3 is a promising tool for drug discovery [55]. Thus, inhibitors that block the NS2B/NS3 interaction could be promising anti-ZIKV drugs.

Niclosamide, an orally bioavailable salicylanilide approved by the FDA, has been used to treat worm infections [19]. It was reportedly a broad-spectrum flavivirus inhibitor. As a category $\mathrm{B}$ drug, niclosamide has an $\mathrm{LD}_{50}$ (median lethal dose) of $5 \mathrm{~g} / \mathrm{kg}$ in rats. A previous study indicated that niclosamide inhibited the $\mathrm{NS} 2 \mathrm{~B} / \mathrm{NS} 3$ interaction in various flaviviruses, presenting an $\mathrm{IC}_{50}$ of $12.3 \pm 0.6 \mu \mathrm{mol} / \mathrm{L}$, while the $\mathrm{EC}_{50}$ against various flaviviruses ranged between 0.4 and $1.1 \mu \mathrm{mol} / \mathrm{L}$ [56]. However, the $\mathrm{CC}_{50}$ (50\% cytotoxic concentration) of niclosamide was $4.8 \mu \mathrm{mol} / \mathrm{L}$, suggesting an unsatisfactory therapeutic index. Researchers observed that the $\mathrm{EC}_{50}$ of niclosamide was $0.22 \mu \mathrm{mol} / \mathrm{L}$ for ZIKV production in human astrocytes [19]. Importantly, niclosamide reduced viral loads in both infected men and non-pregnant women and could protect humans against ZIKV-related complications, such as Guillain-Barré syndrome.

Temoporfin, a photosensitizer drug, has been approved for the treatment of head and neck squamous cell carcinoma [57]. A drug repurposing investigation revealed that temoporfin inhibits ZIKV post-infection. The inhibitory efficiency of temoporfin was almost identical at different ZIKV post-infection times [56]. Furthermore, temoporfin interfered with ZIKV production at approximately $40 \mathrm{nmol} / \mathrm{L}$ in ZIKV-infected human placental epithelial cells (HPECs). Protein thermal shift assays (PTSA) and surface plasmon resonance (SPR) confirmed the inhibition of NS2B/NS3 interaction. In animal models, temoporfin-treated $\mathrm{Balb} / \mathrm{C}$ mice showed a 100 -fold reduction in ZIKV-induced viremia. In the lethal A129 mouse model, temoporfin-treated animals survived without any 
neurological damage after ZIKV infection.

Nitazoxanide, an antiparasitic drug used to treat various helminthic and protozoal infections, possesses broadspectrum antiviral activity against viruses, including flaviviruses [58]. A previous report revealed that nitazoxanide effectively inhibited ZIKV infection in HPECs by reducing protein expression and viral RNA replication [56]. Studies were performed on human neuronal progenitor cells (hNPCs) and the human-induced pluripotent stem cell (iPSC) line HDF9 to investigate nitazoxanide's protective effect. Nitazoxanide markedly reduced ZIKV titers in hNPCs and HDF9 iPSCs cells. Further studies showed that nitazoxanide bound to the NS3 protease domain with an affinity of $7.3 \mu \mathrm{mol} / \mathrm{L}$, indicating its potent ability to inhibit the NS2B/NS3 interaction. Although studies involving pregnant women remained elusive, nitazoxanide reportedly did not affect human fertility or harm the fetus in rats and rabbits [59].

Novobiocin, an antibiotic derived from Streptomyces, is an FDA-approved pregnancy category $\mathrm{C}$ drug [60]. As an aminocoumarin antibiotic, novobiocin targets the GyrB subunit of bacterial DNA gyrase to exert its antibacterial effects $[61,62]$. Novobiocin disrupted NS2B/NS3 interaction and had an $\mathrm{IC}_{50}$ of $14.2 \mu \mathrm{g} / \mathrm{mL}$. The viral titer assay showed that the $\mathrm{EC}_{50}$ in Vero and Huh-7 cells was 26.12 $\mu \mathrm{g} / \mathrm{mL}$ and $38.14 \mu \mathrm{g} / \mathrm{mL}$, respectively. A plaque reduction assay revealed that novobiocin achieved $100 \%$ plaque reduction at $50 \mu \mathrm{g} / \mathrm{mL}$. Molecular docking between novobiocin and the NS2B/NS3 protein showed that three hydrogen bonds were formed at NS2B/NS3 interaction sites, namely the MET51 (NS2B residue), SER81 (NS2B residue), and LYS54 (NS3 residue). In novobiocin-treated mice models, ZIKV viral loads in the blood and most major organ tissues were dramatically reduced than in untreated models.

Bromocriptine is a potent dopamine D2/D3 receptor agonist used to treat galactorrhea and Parkinson's disease $[63,64]$. As an FDA-approved pregnancy category B drug, it is considered safe in pregnant women [28,34]. Bromocriptine had an $\mathrm{EC}_{50}$ of $13 \mu \mathrm{mol} / \mathrm{L}$ in ZIKVinfected Vero cells and was used as an agent to treat ZIKV infections in combination with Intron A (interferon- $\alpha 2 b$ ). The data showed that the combination of bromocriptine and Intron A exhibited a synergistic effect on ZIKV infection. Other studies revealed that bromocriptine interfered with ZIKV replication through a post-entry mechanism. Molecular modeling and a fluorescence-based protease inhibition assay showed that bromocriptine disrupted the ZIKV NS2B/NS3 interaction in a noncompetitive manner, presenting an $\mathrm{IC}_{50}$ of $21.6 \mu \mathrm{mol} / \mathrm{L}$.

Although small-molecule inhibitors targeting the active site NS2B/NS3 are available, further chemical modifications might be required to improve the potency of these inhibitors [65].

\section{Antimalarial (quinoline derivatives)}

An increasing number of studies observed that some antimalarial drugs possess in vitro and in vivo anti-ZIKV activities, including mefloquine, chloroquine, amodiaquine, and hydroxychloroquine.

Chloroquine (CQ), a 4-aminoquinoline derivative, is an inhibitor of autophagy and Toll-like receptors (TLRs) and is widely used to treat malaria and rheumatoid arthritis [66-68]. It can also inhibit various viral infections, such as HIV, dengue virus, Japanese encephalitis virus, and influenza virus, by disrupting the $\mathrm{pH}$-dependent steps of viral replication [69-72]. CQ suppressed in vitro ZIKV replication in Vero cells with an $\mathrm{EC}_{50}$ of $9.82 \mu \mathrm{mol} / \mathrm{L}$ [28,73-75]. It reversed morphological changes induced by ZIKV infection in mouse neurospheres [28]. CQ interfered with the early stage of the ZIKV replication cycle in the fusion of envelope proteins with the endosome membrane. Li et al. found that CQ inhibited ZIKV infection in vitro by blocking virus internalization [73]. In an animal model, CQ protected fetal mice from microcephaly caused by ZIKV infection. Using interferon signaling-competent SJL mice, Shiryaev et al. demonstrated that CQ attenuated vertical transmission, which reduced the ZIKV load in the fetal brain by over 95\% [74]. CQ is a class C FDAapproved drug that can cross the placental barrier [76]. Enhanced permeability of the placental barrier benefits therapy in pregnant women.

Hydroxychloroquine (HCQ), a hydroxyl analog of chloroquine, is a class C FDA-approved drug that is used to treat malaria, systemic lupus erythematosus, and rheumatoid arthritis [68,77-79]. Both HCQ and CQ are derivatives of a 4-aminoquinoline nucleus [80]. HCQ is proposed to be a safer CQ alternative [81]. The concentrations of HCQ in the brain are 4-30 times higher than in plasma, suggesting a favorable pharmacokinetic profile against ZIKV infection in hNPCs [74,82]. By alkalizing intracellular acidic organelles, HCQ exerts antibacterial and antiviral activities [83,84]. Furthermore, HCQ blocks the viral entry step and protein glycosylation [84]. Cao et al. observed that HCQ could reduce ZIKV infection in the mouse placenta and relieve placental damage in the fetal head [85]. This result might be associated with decreased placental autophagy, which limits vertical maternal-fetal transmission. Kumar et al. indicated that HCQ suppressed ZIKV replication by reducing the NS2B/ NS3 protease activity [52]. A normal HCQ dosage during pregnancy is not related to fetal malformations [86] and not associated with other adverse pregnancy outcomes, such as stillbirth, low birth weight, and prematurity. However, the current results are insufficient to evaluate its fetotoxicity.

Mefloquine (MQ), a quinine derivative, is a class B FDA-approved drug widely used in malaria prevention $[87,88]$. Additionally, MQ has anti-cancer, anti- 
tuberculosis, and antiviral activities [89-91]. BarbosaLima et al. identified that MQ inhibited ZIKV replication in Vero and HeLa cells, with $\mathrm{EC}_{50}$ values of $3.6 \mu \mathrm{mol} / \mathrm{L}$ and $10 \mu \mathrm{mol} / \mathrm{L}$, respectively [18,92]. However, MQ was found to be cytotoxic in an hNSC cell line (K048) [18]. MQ demonstrated better blood-brain barrier (BBB) penetration than CQ [66]. The anti-ZIKV activity of MQ requires further evaluation.

Amodiaquine (AQ), a 4-aminoquinoline derivative, is another inhibitor of autophagy for malaria therapy [93]. AQ reportedly inhibited ZIKV replication in hNPCs cells, with an $\mathrm{EC}_{50}$ of $2.8 \mu \mathrm{mol} / \mathrm{L}$ in vitro, and inhibited $\mathrm{ZIKV}$ infection in the SCID-beige mouse brain in vivo [94]. A report by Han et al. revealed that AQ targeted an early step of viral replication [75]. Importantly, AQ is safe during pregnancy and has been used to inhibit the Ebola virus at clinically relevant doses [95]. However, AQ has been restricted in many fields due to its hepatic and hematological toxicities [96]. Therefore, the application of AQ for ZIKV infections requires further investigation.

\section{Antibiotics}

Azithromycin (AZ) is a macrolide antibiotic with no side effects on pregnancy and fetal development [97]. By screening FDA-approved compounds for anti-ZIKV treatment in a glial cell line, Retallack et al. found that AZ inhibited viral production and virus-mediated cell death [98]. In U87 cells, AZ reduced ZIKV infection, presenting an $\mathrm{EC}_{50}$ of $2-3 \mu \mathrm{mol} / \mathrm{L}$, whereas in human pluripotent stem cell (hPSC)-derived astrocytes, the $\mathrm{EC}_{50}$ was 15 $\mu \mathrm{mol} / \mathrm{L}$. AZ was found to reach $19-151 \mathrm{ng} / \mathrm{mL}$ in fetal tissues and the adult human brain $[99,100]$. The mechanism underlying the action of $\mathrm{AZ}$ against ZIKV remains unclear.

Daptomycin is a cyclic lipopeptide antibiotic with potent antibacterial activity against skin and bloodstream infections [101-103]. Daptomycin inhibits ZIKV infection with an $\mathrm{EC}_{50}$ of $1.0 \mu \mathrm{mol} / \mathrm{L}$ in Huh-7 cells, but the inhibitory activities in HeLa and JEG3 cells were weak [18]. Furthermore, daptomycin reduced ZIKV replication in hNSC and human amnion epithelial cells (hAECs). The concentration of daptomycin in plasma ranged between 19 and $199 \mu \mathrm{g} / \mathrm{mL}$ [104]. Although daptomycin is a class B FDA-approved drug, limited case reports in neonates have been recorded [102]. No reports regarding the anti-ZIKV activity of daptomycin in vivo are currently available.

\section{Others}

By screening drugs for repurposing, several compounds that could inhibit ZIKV infection have been identified, and the various mechanisms are presented.
Emricasan, a selective pan-caspase inhibitor, has been used to treat ZIKV infection in combination with other anti-ZIKV-replication drugs $[105,106]$. Emricasan inhibited neural cell death induced by caspases but failed to inhibit ZIKV replication [107]. Subsequent studies observed that PHA-690509, a cyclin-dependent kinase inhibitor, possessed good inhibitory activity on ZIKV proliferation. Combination of emricasan and PHA-690509 showed synergistic effects on ZIKV infection. Emricasan could induce the recovery of ZIKV-infected cells by inhibiting caspase when combined with PHA-690509. Emricasan is currently undergoing phase II clinical trials $[108,109]$.

Suramin is not approved by the FDA; it is a polyanionic compound used to treat African trypanosomiasis and kill the adult Onchocerca via an unknown mechanism [110]. Suramin could protect Vero cells against ZIKV-induced death, presenting an $\mathrm{EC}_{50}$ of $39.8 \mu \mathrm{mol} / \mathrm{L}$. Albulescu et al. demonstrated that suramin could decrease the intracellular ZIKV RNA copies by interfering with both the virus attachment and release stage [111].

After screening 774 FDA-approved drugs, mycophenolic acid, sertraline, and mefloquine were found to be effective in inhibiting ZIKV infection in Huh-7 cells [26]. HeLa and JEG3 cells were also used for further anti-ZIKV investigations. Mycophenolic acid, an immunosuppressant drug, could inhibit ZIKV infection in HeLa and JEG3 cells. In hAECs, both sertraline and mefloquine exhibited strong inhibition against ZIKV infection at $16 \mu \mathrm{mol} / \mathrm{L}$; none of these drugs were cytotoxic at this concentration [18].

\section{Conclusions}

Identifying novel therapeutic activities of existing drugs is a rapid approach to curb emergency outbreaks of ZIKV infections. Several clinically approved drugs manifest antiZIKV activities in vivo and are now undergoing clinical trials $[74,85]$. We discussed the features of these drugs for their potential use in ZIKV infections. Considering that the unique patients include pregnant women and newborns, further work is needed to complete the clinical trials of these drugs. The risk of repurposing drugs needs to be weighed against the risk of no treatment. Moreover, some clinically approved drugs showed anti-ZIKV activities at impracticable inhibition concentrations $(>100 \mu \mathrm{mol} / \mathrm{L})$ or possessed cytotoxicity, indicating that they could never be utilized in pregnant women and newborns $[35,61]$. Thus, the immediate use of these repurposed clinical drugs in humans seems unlikely. Medicinal chemistry approaches should be used to improve or optimize these drugs. Additionally, further development of novel anti-ZIKV compounds and combination therapies is needed to treat ZIKV infections.

By repurposing clinical drugs, we are advancing the 
fight against ZIKV. We believe that the development of highly effective anti-ZIKV drugs is possible.

\section{Acknowledgements}

This work was supported by CAMS Major Collaborative Innovation Project (No. 2016-I2M-1-011), National Natural Science Foundation of China (No. 81773784), Beijing Nova Program (No. Z181100006218075), Basic Scientific Research Program of CAMS (No. 2018RC350005), and Drug Innovation Major Project (No. 2018ZX09711001-002-002).

\section{Compliance with ethics guidelines}

Weibao Song, Hongjuan Zhang, Yu Zhang, Rui Li, Yanxing Han, Yuan Lin, and Jiandong Jiang declare that they have no financial conflicts of interest. This manuscript is a review article and does not involve a research protocol requiring approval by the relevant institutional review board or ethics committee.

Open Access This article is licensed under a Creative Commons Attribution 4.0 International License, which permits use, sharing, adaptation, distribution and reproduction in any medium or format, as long as you give appropriate credit to the original author(s) and the source, provide a link to the Creative Commons license, and indicate if changes were made.

The images or other third party material in this article are included in the article's Creative Commons license, unless indicated otherwise in a credit line to the material. If material is not included in the article's Creative Commons license and your intended use is not permitted by statutory regulation or exceeds the permitted use, you will need to obtain permission directly from the copyright holder.

To view a copy of this license, visit https://creativecommons.org/ licenses/by/4.0/.

\section{References}

1. Musso D, Gubler DJ. Zika virus. Clin Microbiol Rev 2016; 29(3): 487-524

2. Cao-Lormeau VM, Blake A, Mons S, Lastère S, Roche C, Vanhomwegen J, Dub T, Baudouin L, Teissier A, Larre P, Vial AL, Decam C, Choumet V, Halstead SK, Willison HJ, Musset L, Manuguerra JC, Despres P, Fournier E, Mallet HP, Musso D, Fontanet A, Neil J, Ghawché F. Guillain-Barré syndrome outbreak associated with Zika virus infection in French Polynesia: a casecontrol study. Lancet 2016; 387(10027): 1531-1539

3. Blohm GM, Lednicky JA, Márquez M, White SK, Loeb JC, Pacheco CA, Nolan DJ, Paisie T, Salemi M, Rodríguez-Morales AJ, Glenn Morris J Jr, Pulliam JRC, Paniz-Mondolfi AE. Evidence for mother-to-child transmission of Zika virus through breast milk. Clin Infect Dis 2018; 66(7): 1120-1121

4. Heymann DL, Hodgson A, Sall AA, Freedman DO, Staples JE, Althabe F, Baruah K, Mahmud G, Kandun N, Vasconcelos PF,
Bino S, Menon KU. Zika virus and microcephaly: why is this situation a PHEIC? Lancet 2016; 387(10020): 719-721

5. Haddow AD, Schuh AJ, Yasuda CY, Kasper MR, Heang V, Huy R, Guzman H, Tesh RB, Weaver SC. Genetic characterization of Zika virus strains: geographic expansion of the Asian lineage. PLoS Negl Trop Dis 2012; 6(2): e1477

6. Sinigaglia A, Riccetti S, Trevisan M, Barzon L. In silico approaches to Zika virus drug discovery. Expert Opin Drug Discov 2018; 13(9): 825-835

7. Baz M, Boivin G. Antiviral agents in development for Zika virus infections. Pharmaceuticals (Basel) 2019; 12(3): E101

8. Mastrangelo E, Milani M, Bollati M, Selisko B, Peyrane F, Pandini V, Sorrentino G, Canard B, Konarev PV, Svergun DI, de Lamballerie X, Coutard B, Khromykh AA, Bolognesi M. Crystal structure and activity of Kunjin virus NS3 helicase; protease and helicase domain assembly in the full length NS3 protein. J Mol Biol 2007; 372(2): 444-455

9. Lei J, Hansen G, Nitsche C, Klein CD, Zhang L, Hilgenfeld R. Crystal structure of Zika virus NS2B-NS3 protease in complex with a boronate inhibitor. Science 2016; 353(6298): 503-505

10. Zhao B, Yi G, Du F, Chuang YC, Vaughan RC, Sankaran B, Kao CC, Li P. Structure and function of the Zika virus full-length NS5 protein. Nat Commun 2017; 8(1): 14762

11. Phoo WW, Li Y, Zhang Z, Lee MY, Loh YR, Tan YB, Ng EY, Lescar J, Kang C, Luo D. Structure of the NS2B-NS3 protease from Zika virus after self-cleavage. Nat Commun 2016; 7(1): 13410

12. Onorati M, Li Z, Liu F, Sousa AMM, Nakagawa N, Li M, Dell'Anno MT, Gulden FO, Pochareddy S, Tebbenkamp ATN, Han W, Pletikos M, Gao T, Zhu Y, Bichsel C, Varela L, SzigetiBuck K, Lisgo S, Zhang Y, Testen A, Gao XB, Mlakar J, Popovic M, Flamand M, Strittmatter SM, Kaczmarek LK, Anton ES, Horvath TL, Lindenbach BD, Sestan N. Zika virus disrupts phospho-TBK1 localization and mitosis in human neuroepithelial stem cells and radial glia. Cell Rep 2016; 16(10): 2576-2592

13. Zou J, Shi PY. Strategies for Zika drug discovery. Curr Opin Virol 2019; 35: 19-26

14. Shiryaev SA, Farhy C, Pinto A, Huang CT, Simonetti N, Elong Ngono A, Dewing A, Shresta S, Pinkerton AB, Cieplak P, Strongin $\mathrm{AY}$, Terskikh AV. Characterization of the Zika virus twocomponent NS2B-NS3 protease and structure-assisted identification of allosteric small-molecule antagonists. Antiviral Res 2017; 143: 218-229

15. Elfiky AA, Elshemey WM. Molecular dynamics simulation revealed binding of nucleotide inhibitors to ZIKV polymerase over 444 nanoseconds. J Med Virol 2018; 90(1): 13-18

16. Gadea G, Bos S, Krejbich-Trotot P, Clain E, Viranaicken W, ElKalamouni $C$, Mavingui $P$, Desprès $P$. A robust method for the rapid generation of recombinant Zika virus expressing the GFP reporter gene. Virology 2016; 497: 157-162

17. Xie X, Zou J, Shan C, Yang Y, Kum DB, Dallmeier K, Neyts J, Shi PY. Zika virus replicons for drug discovery. EBioMedicine 2016; 12: $156-160$

18. Barrows NJ, Campos RK, Powell ST, Prasanth KR, Schott-Lerner G, Soto-Acosta R, Galarza-Muñoz G, McGrath EL, Urrabaz-Garza R, Gao J, Wu P, Menon R, Saade G, Fernandez-Salas I, Rossi SL, Vasilakis N, Routh A, Bradrick SS, Garcia-Blanco MA. A screen 
of FDA-approved drugs for inhibitors of Zika virus infection. Cell Host Microbe 2016; 20(2): 259-270

19. Xu M, Lee EM, Wen Z, Cheng Y, Huang WK, Qian X, Tcw J, Kouznetsova J, Ogden SC, Hammack C, Jacob F, Nguyen HN, Itkin M, Hanna C, Shinn P, Allen C, Michael SG, Simeonov A, Huang W, Christian KM, Goate A, Brennand KJ, Huang R, Xia M, Ming GL, Zheng W, Song H, Tang H. Identification of smallmolecule inhibitors of Zika virus infection and induced neural cell death via a drug repurposing screen. Nat Med 2016; 22(10): 11011107

20. Wilder-Smith A, Vannice K, Durbin A, Hombach J, Thomas SJ, Thevarjan I, Simmons CP. Zika vaccines and therapeutics: landscape analysis and challenges ahead. BMC Med 2018; 16 (1): 84

21. Diamond MS, Ledgerwood JE, Pierson TC. Zika virus vaccine development: progress in the face of new challenges. Annu Rev Med 2019; 70(1): 121-135

22. Allison M. NCATS launches drug repurposing program. Nat Biotechnol 2012; 30(7): 571-572

23. Konreddy AK, Rani GU, Lee K, Choi Y. Recent drug-repurposingdriven advances in the discovery of novel antibiotics. Curr Med Chem 2019; 26(28): 5363-5388

24. Dandu K, Kallamadi PR, Thakur SS, Rao CM. Drug repurposing for retinoblastoma: recent advances. Curr Top Med Chem 2019; 19 (17): 1535-1544

25. Han Y, Mesplède T. Investigational drugs for the treatment of Zika virus infection: a preclinical and clinical update. Expert Opin Investig Drugs 2018; 27(12): 951-962

26. Devillers J. Repurposing drugs for use against Zika virus infection. SAR QSAR Environ Res 2018; 29(2): 103-115

27. Schlitzer M. Malaria chemotherapeutics part I: history of antimalarial drug development, currently used therapeutics, and drugs in clinical development. ChemMedChem 2007; 2(7): 944986

28. Delvecchio R, Higa LM, Pezzuto P, Valadão AL, Garcez PP, Monteiro FL, Loiola EC, Dias AA, Silva FJ, Aliota MT, Caine EA, Osorio JE, Bellio M, O'Connor DH, Rehen S, de Aguiar RS, Savarino A, Campanati L, Tanuri A. Chloroquine, an endocytosis blocking agent, inhibits Zika virus infection in different cell models. Viruses 2016; 8(12): E322

29. Sacramento CQ, de Melo GR, de Freitas CS, Rocha N, Hoelz LV, Miranda M, Fintelman-Rodrigues N, Marttorelli A, Ferreira AC, Barbosa-Lima G, Abrantes JL, Vieira YR, Bastos MM, de Mello Volotão E, Nunes EP, Tschoeke DA, Leomil L, Loiola EC, Trindade P, Rehen SK, Bozza FA, Bozza PT, Boechat N, Thompson FL, de Filippis AM, Brüning K, Souza TM. The clinically approved antiviral drug sofosbuvir inhibits Zika virus replication. Sci Rep 2017; 7(1): 40920

30. Li Z, Brecher M, Deng YQ, Zhang J, Sakamuru S, Liu B, Huang R, Koetzner CA, Allen CA, Jones SA, Chen H, Zhang NN, Tian M, Gao F, Lin Q, Banavali N, Zhou J, Boles N, Xia M, Kramer LD, Qin CF, Li H. Existing drugs as broad-spectrum and potent inhibitors for Zika virus by targeting NS2B-NS3 interaction. Cell Res 2017; 27(8): 1046-1064

31. Patel MN, Halling-Brown MD, Tym JE, Workman P, Al-Lazikani B. Objective assessment of cancer genes for drug discovery. Nat Rev Drug Discov 2013; 12(1): 35-50
32. Napolitano F, Zhao Y, Moreira VM, Tagliaferri R, Kere J, D'Amato M, Greco D. Drug repositioning: a machine-learning approach through data integration. J Cheminform 2013; 5(1): 30

33. Pujol A, Mosca R, Farrés J, Aloy P. Unveiling the role of network and systems biology in drug discovery. Trends Pharmacol Sci 2010; 31(3): 115-123

34. Bullard-Feibelman KM, Govero J, Zhu Z, Salazar V, Veselinovic M, Diamond MS, Geiss BJ. The FDA-approved drug sofosbuvir inhibits Zika virus infection. Antiviral Res 2017; 137: 134-140

35. Mehrotra PK, Kitchlu S, Dwivedi A, Agnihotri PK, Srivastava S, Roy R, Bhaduri AP. Emetine ditartrate: a possible lead for emergency contraception. Contraception 2004; 69(5): 379-387

36. Novac N. Challenges and opportunities of drug repositioning. Trends Pharmacol Sci 2013; 34(5): 267-272

37. Chopra D, Bhandari B. Sofosbuvir: really meets the unmet needs for hepatitis C treatment? Infect Disord Drug Targets 2020; 20(1): 2-15

38. Bhatia HK, Singh H, Grewal N, Natt NK. Sofosbuvir: a novel treatment option for chronic hepatitis $\mathrm{C}$ infection. J Pharmacol Pharmacother 2014; 5(4): 278-284

39. Murakami E, Tolstykh T, Bao H, Niu C, Steuer HM, Bao D, Chang W, Espiritu C, Bansal S, Lam AM, Otto MJ, Sofia MJ, Furman PA. Mechanism of activation of PSI-7851 and its diastereoisomer PSI7977. J Biol Chem 2010; 285(45): 34337-34347

40. Herbst DA Jr, Reddy KR. Sofosbuvir, a nucleotide polymerase inhibitor, for the treatment of chronic hepatitis $\mathrm{C}$ virus infection. Expert Opin Investig Drugs 2013; 22(4): 527-536

41. Liu J, Du J, Wang P, Nagarathnam D, Espiritu CL, Bao H, Murakami E, Furman PA, Sofia MJA. A 2'-deoxy-2'-fluoro-2'-Cmethyl uridine cyclopentyl carbocyclic analog and its phosphoramidate prodrug as inhibitors of HCV NS5B polymerase. Nucleosides Nucleotides Nucleic Acids 2012; 31(4): 277-285

42. Mumtaz N, Jimmerson LC, Bushman LR, Kiser JJ, Aron G, Reusken CBEM, Koopmans MPG, van Kampen JJA. Cell-line dependent antiviral activity of sofosbuvir against Zika virus. Antiviral Res 2017; 146: 161-163

43. Xu HT, Hassounah SA, Colby-Germinario SP, Oliveira M, Fogarty C, Quan Y, Han Y, Golubkov O, Ibanescu I, Brenner B, Stranix BR, Wainberg MA. Purification of Zika virus RNAdependent RNA polymerase and its use to identify small-molecule Zika inhibitors. J Antimicrob Chemother 2017; 72(3): 727-734

44. Matthews H, Usman-Idris M, Khan F, Read M, Nirmalan N. Drug repositioning as a route to anti-malarial drug discovery: preliminary investigation of the in vitro anti-malarial efficacy of emetine dihydrochloride hydrate. Malar J 2013; 12(1): 359

45. Krstin S, Mohamed T, Wang X, Wink M. How do the alkaloids emetine and homoharringtonine kill trypanosomes? An insight into their molecular modes of action. Phytomedicine 2016; 23(14): $1771-1777$

46. Saif M. Treatment of amoebiasis. J Egypt Public Health Assoc 1973; 48(3): 159-166

47. Yang S, Xu M, Lee EM, Gorshkov K, Shiryaev SA, He S, Sun W, Cheng YS, Hu X, Tharappel AM, Lu B, Pinto A, Farhy C, Huang CT, Zhang Z, Zhu W, Wu Y, Zhou Y, Song G, Zhu H, Shamim K, Martínez-Romero C, García-Sastre A, Preston RA, Jayaweera DT, Huang R, Huang W, Xia M, Simeonov A, Ming G, Qiu X, Terskikh AV, Tang H, Song H, Zheng W. Emetine inhibits Zika 
and Ebola virus infections through two molecular mechanisms: inhibiting viral replication and decreasing viral entry. Cell Discov 2018; 4(1): 31

48. Lin Y, Zhang H, Song W, Si S, Han Y, Jiang J. Identification and characterization of Zika virus NS5 RNA-dependent RNA polymerase inhibitors. Int J Antimicrob Agents 2019; 54(4): 502-506

49. Helms S, Miller A. Natural treatment of chronic rhinosinusitis. Altern Med Rev 2006; 11(3): 196-207

50. Julander JG, Siddharthan V, Evans J, Taylor R, Tolbert K, Apuli C, Stewart J, Collins P, Gebre M, Neilson S, Van Wettere A, Lee YM, Sheridan WP, Morrey JD, Babu YS. Efficacy of the broadspectrum antiviral compound BCX4430 against Zika virus in cell culture and in a mouse model. Antiviral Res 2017; 137: 14-22

51. Munjal A, Khandia R, Dhama K, Sachan S, Karthik K, Tiwari R, Malik YS, Kumar D, Singh RK, Iqbal HMN, Joshi SK. Advances in developing therapies to combat Zika virus: current knowledge and future perspectives. Front Microbiol 2017; 8: 1469

52. Kumar A, Liang B, Aarthy M, Singh SK, Garg N, Mysorekar IU, Giri R. Hydroxychloroquine inhibits Zika virus NS2B-NS3 protease. ACS Omega 2018; 3(12): 18132-18141

53. Murray CL, Jones CT, Rice CM. Architects of assembly: roles of Flaviviridae non-structural proteins in virion morphogenesis. Nat Rev Microbiol 2008; 6(9): 699-708

54. Erbel P, Schiering N, D'Arcy A, Renatus M, Kroemer M, Lim SP, Yin Z, Keller TH, Vasudevan SG, Hommel U. Structural basis for the activation of flaviviral NS3 proteases from dengue and West Nile virus. Nat Struct Mol Biol 2006; 13(4): 372-373

55. Kang C, Keller TH, Luo D. Zika virus protease: an antiviral drug target. Trends Microbiol 2017; 25(10): 797-808

56. Li Z, Brecher M, Deng YQ, Zhang J, Sakamuru S, Liu B, Huang R, Koetzner CA, Allen CA, Jones SA, Chen H, Zhang NN, Tian M, Gao F, Lin Q, Banavali N, Zhou J, Boles N, Xia M, Kramer LD, Qin CF, Li H. Existing drugs as broad-spectrum and potent inhibitors for Zika virus by targeting NS2B-NS3 interaction. Cell Res 2017; 27(8): 1046-1064

57. Yakavets I, Lassalle HP, Scheglmann D, Wiehe A, Zorin V, Bezdetnaya L. Temoporfin-in-cyclodextrin-in-liposome - a new approach for anticancer drug delivery: the optimization of composition. Nanomaterials (Basel) 2018; 8(10): E847

58. Rossignol JF. Nitazoxanide: a first-in-class broad-spectrum antiviral agent. Antiviral Res 2014; 110: 94-103

59. Shi Z, Wei J, Deng X, Li S, Qiu Y, Shao D, Li B, Zhang K, Xue F, Wang X, Ma Z. Nitazoxanide inhibits the replication of Japanese encephalitis virus in cultured cells and in a mouse model. Virol J 2014; 11(1): 10

60. Rizk OH, Bekhit MG, Hazzaa AAB, El-Khawass EM, Abdelwahab IA. Synthesis, antibacterial evaluation, and DNA gyrase inhibition profile of some new quinoline hybrids. Arch Pharm (Weinheim) 2019; 352(10): e1900086

61. Yuan S, Chan JF, den-Haan H, Chik KK, Zhang AJ, Chan CC, Poon VK, Yip CC, Mak WW, Zhu Z, Zou Z, Tee KM, Cai JP, Chan KH, de la Peña J, Pérez-Sánchez H, Cerón-Carrasco JP, Yuen KY. Structure-based discovery of clinically approved drugs as Zika virus NS2B-NS3 protease inhibitors that potently inhibit Zika virus infection in vitro and in vivo. Antiviral Res 2017; 145: 33-43

62. Flatman RH, Eustaquio A, Li SM, Heide L, Maxwell A. Structureactivity relationships of aminocoumarin-type gyrase and topoi- somerase IV inhibitors obtained by combinatorial biosynthesis. Antimicrob Agents Chemother 2006; 50(4): 1136-1142

63. Chan JF, Chik KK, Yuan S, Yip CC, Zhu Z, Tee KM, Tsang JO, Chan CC, Poon VK, Lu G, Zhang AJ, Lai KK, Chan KH, Kao RY, Yuen KY. Novel antiviral activity and mechanism of bromocriptine as a Zika virus NS2B-NS3 protease inhibitor. Antiviral Res 2017; 141: 29-37

64. Ginther OJ, Santos VG, Mir RA, Beg MA. Role of LH in the progesterone increase during the bromocriptine-induced prolactin decrease in heifers. Theriogenology 2012; 78(9): 1969-1976

65. Li Y, Zhang Z, Phoo WW, Loh YR, Li R, Yang HY, Jansson AE, Hill J, Keller TH, Nacro K, Luo D, Kang C. Structural insights into the inhibition of Zika virus NS2B-NS3 protease by a smallmolecule inhibitor. Structure 2018; 26(4): 555-564.e3

66. Geng Y, Kohli L, Klocke BJ, Roth KA. Chloroquine-induced autophagic vacuole accumulation and cell death in glioma cells is p53 independent. Neuro Oncol 2010; 12(5): 473-481

67. Zhu X, Pan Y, Li Y, Jiang Y, Shang H, Gowda DC, Cui L, Cao Y. Targeting Toll-like receptors by chloroquine protects mice from experimental cerebral malaria. Int Immunopharmacol 2012; 13(4): 392-397

68. Browning DJ. Pharmacology of chloroquine and hydroxychloroquine. In: Hydroxychloroquine and Chloroquine Retinopathy. New York: Springer, 2014: 35-63

69. Tsai WP, Nara PL, Kung HF, Oroszlan S. Inhibition of human immunodeficiency virus infectivity by chloroquine. AIDS Res Hum Retroviruses 1990; 6(4): 481-489

70. Farias KJ, Machado PR, da Fonseca BA. Chloroquine inhibits dengue virus type 2 replication in Vero cells but not in C6/36 cells. ScientificWorldJournal 2013; 2013: 282734

71. Zhu YZ, Xu QQ, Wu DG, Ren H, Zhao P, Lao WG, Wang Y, Tao QY, Qian XJ, Wei YH, Cao MM, Qi ZT. Japanese encephalitis virus enters rat neuroblastoma cells via a $\mathrm{pH}$-dependent, dynamin and caveola-mediated endocytosis pathway. J Virol 2012; 86(24): 13407-13422

72. Ooi EE, Chew JS, Loh JP, Chua RC. In vitro inhibition of human influenza A virus replication by chloroquine. Virol J 2006; 3(1): 39

73. Zhu Y, Lin Y, Liu X, Hu W, Wang Y. Identification of AcAP5 as a novel factor Xa inhibitor with both direct and allosteric inhibition. Biochem Biophys Res Commun 2017; 483(1): 495-501

74. Shiryaev SA, Mesci P, Pinto A, Fernandes I, Sheets N, Shresta S, Farhy C, Huang CT, Strongin AY, Muotri AR, Terskikh AV. Repurposing of the anti-malaria drug chloroquine for Zika virus treatment and prophylaxis. Sci Rep 2017; 7(1): 15771

75. Han Y, Mesplède T, Xu H, Quan Y, Wainberg MA. The antimalarial drug amodiaquine possesses anti-Zika virus activities. J Med Virol 2018; 90(5): 796-802

76. Law I, Ilett KF, Hackett LP, Page-Sharp M, Baiwog F, Gomorrai S, Mueller I, Karunajeewa HA, Davis TM. Transfer of chloroquine and desethylchloroquine across the placenta and into milk in Melanesian mothers. Br J Clin Pharmacol 2008; 65(5): 674-679

77. Ruiz-Irastorza G, Khamashta MA. Hydroxychloroquine: the cornerstone of lupus therapy. Lupus 2008; 17(4): 271-273

78. Dörner T. Hydroxychloroquine in SLE: old drug, new perspectives. Nat Rev Rheumatol 2010; 6(1): 10-11

79. Ben-Zvi I, Kivity S, Langevitz P, Shoenfeld Y. Hydroxychloroquine: from malaria to autoimmunity. Clin Rev Allergy Immunol 
2012; 42(2): 145-153

80. Berliner RW, Earle DP Jr, Taggart JV, Zubrod CG, Welch WJ, Conan NJ, Bauman E, Scudder ST, Shannon JA. Studies on the chemotherapy of the human malarias; of the human malarias the physiological disposition, antimalarial activity, and toxicity of several derivatives of 4-aminoquinoline. J Clin Invest 1948; 27(3): 98-107

81. Tzekov R. Ocular toxicity due to chloroquine and hydroxychloroquine: electrophysiological and visual function correlates. Doc Ophthalmol 2005; 110(1): 111-120

82. Titus EO. Recent developments in the understanding of the pharmacokinetics and mechanism of action of chloroquine. Ther Drug Monit 1989; 11(4): 369-379

83. O’Neill PM, Bray PG, Hawley SR, Ward SA, Park BK. 4Aminoquinolines - past, present, and future: a chemical perspective. Pharmacol Ther 1998; 77(1): 29-58

84. Rolain JM, Colson P, Raoult D. Recycling of chloroquine and its hydroxyl analogue to face bacterial, fungal and viral infections in the 21st century. Int J Antimicrob Agents 2007; 30(4): 297-308

85. Cao B, Parnell LA, Diamond MS, Mysorekar IU. Inhibition of autophagy limits vertical transmission of Zika virus in pregnant mice. J Exp Med 2017; 214(8): 2303-2313

86. Kaplan YC, Ozsarfati J, Nickel C, Koren G. Reproductive outcomes following hydroxychloroquine use for autoimmune diseases: a systematic review and meta-analysis. $\mathrm{Br} \mathrm{J}$ Clin Pharmacol 2016; 81(5): 835-848

87. Pukrittayakamee S, Imwong $\mathrm{M}$, Looareesuwan $\mathrm{S}$, White NJ. Therapeutic responses to antimalarial and antibacterial drugs in vivax malaria. Acta Trop 2004; 89(3): 351-356

88. Palmer KJ, Holliday SM, Brogden RN. Mefloquine. A review of its antimalarial activity, pharmacokinetic properties and therapeutic efficacy. Drugs 1993; 45(3): 430-475

89. Liu Y, Chen S, Xue R, Zhao J, Di M. Mefloquine effectively targets gastric cancer cells through phosphatase-dependent inhibition of PI3K/Akt/mTOR signaling pathway. Biochem Biophys Res Commun 2016; 470(2): 350-355

90. Krieger D, Vesenbeckh S, Schönfeld N, Bettermann G, Bauer TT, Rüssmann H, Mauch H. Mefloquine as a potential drug against multidrug-resistant tuberculosis. Eur Respir J 2015; 46(5): 15031505

91. Brickelmaier M, Lugovskoy A, Kartikeyan R, Reviriego-Mendoza MM, Allaire N, Simon K, Frisque RJ, Gorelik L. Identification and characterization of mefloquine efficacy against $\mathrm{JC}$ virus in vitro. Antimicrob Agents Chemother 2009; 53(5): 1840-1849

92. Barbosa-Lima G, Moraes AM, Araújo ADS, da Silva ET, de Freitas CS, Vieira YR, Marttorelli A, Neto JC, Bozza PT, de Souza MVN, Souza TML. 2,8-bis(trifluoromethyl)quinoline analogs show improved anti-Zika virus activity, compared to mefloquine. Eur J Med Chem 2017; 127: 334-340

93. Qiao S, Tao S, Rojo de la Vega M, Park SL, Vonderfecht AA, Jacobs SL, Zhang DD, Wondrak GT. The antimalarial amodiaquine causes autophagic-lysosomal and proliferative blockade sensitizing human melanoma cells to starvation- and chemotherapy-induced cell death. Autophagy 2013; 9(12): 2087-2102

94. Zhou T, Tan L, Cederquist GY, Fan Y, Hartley BJ, Mukherjee S, Tomishima M, Brennand KJ, Zhang Q, Schwartz RE, Evans T, Studer L, Chen S. High-content screening in hPSC-neural progenitors identifies drug candidates that inhibit Zika virus infection in fetal-like organoids and adult brain. Cell Stem Cell 2017; 21(2): 274-283.e5

95. Zilbermintz L, Leonardi W, Jeong SY, Sjodt M, McComb R, Ho CL, Retterer C, Gharaibeh D, Zamani R, Soloveva V, Bavari S, Levitin A, West J, Bradley KA, Clubb RT, Cohen SN, Gupta V, Martchenko M. Identification of agents effective against multiple toxins and viruses by host-oriented cell targeting. Sci Rep 2015; 5 (1): 13476

96. Parhizgar AR, Tahghighi A. Introducing new antimalarial analogues of chloroquine and amodiaquine: a narrative review. Iran J Med Sci 2017; 42(2): 115-128

97. Sarkar M, Woodland C, Koren G, Einarson AR. Pregnancy outcome following gestational exposure to azithromycin. BMC Pregnancy Childbirth 2006; 6(1): 18

98. Retallack H, Di Lullo E, Arias C, Knopp KA, Laurie MT, Sandoval-Espinosa C, Mancia Leon WR, Krencik R, Ullian EM, Spatazza J, Pollen AA, Mandel-Brehm C, Nowakowski TJ, Kriegstein AR, DeRisi JL. Zika virus cell tropism in the developing human brain and inhibition by azithromycin. Proc Natl Acad Sci USA 2016; 113(50): 14408-14413

99. Ramsey PS, Vaules MB, Vasdev GM, Andrews WW, Ramin KD. Maternal and transplacental pharmacokinetics of azithromycin. Am J Obstet Gynecol 2003; 188(3): 714-718

100. Kemp MW, Miura Y, Payne MS, Jobe AH, Kallapur SG, Saito M, Stock SJ, Spiller OB, Ireland DJ, Yaegashi N, Clarke M, Hahne D, Rodger J, Keelan JA, Newnham JP. Maternal intravenous administration of azithromycin results in significant fetal uptake in a sheep model of second trimester pregnancy. Antimicrob Agents Chemother 2014; 58(11): 6581-6591

101. Enoch DA, Bygott JM, Daly ML, Karas JA. Daptomycin. J Infect 2007; 55(3): 205-213

102. Eisenstein BI. Lipopeptides, focusing on daptomycin, for the treatment of Gram-positive infections. Expert Opin Investig Drugs 2004; 13(9): 1159-1169

103. Shoemaker DM, Simou J, Roland WE. A review of daptomycin for injection (Cubicin) in the treatment of complicated skin and skin structure infections. Ther Clin Risk Manag 2006; 2(2): 169-174

104. Dei Cas M, Casagni E, Gambaro V, Cesari E, Roda G. Determination of daptomycin in human plasma and breast milk by UPLC/MS-MS. J Chromatogr B Analyt Technol Biomed Life Sci 2019; 1116: 38-43

105. McCall M, Toso C, Emamaullee J, Pawlick R, Edgar R, Davis J, Maciver A, Kin T, Arch R, Shapiro AM. The caspase inhibitor IDN-6556 (PF3491390) improves marginal mass engraftment after islet transplantation in mice. Surgery 2011; 150(1): 48-55

106. Haddad JJ. Current opinion on 3-[2-[(2-tert-butyl-phenylaminooxalyl)-amino]-propionylamino]-4-oxo-5-(2,3,5,6-tetrafluoro-phenoxy)-pentanoic acid, an investigational drug targeting caspases and caspase-like proteases: the clinical trials in sight and recent anti-inflammatory advances. Recent Pat Inflamm Allergy Drug Discov 2013; 7(3): 229-258

107. Hoglen NC, Chen LS, Fisher CD, Hirakawa BP, Groessl T, Contreras PC. Characterization of IDN-6556 (3-[2-(2-tert-butylphenylaminooxalyl)-amino]-propionylamino]-4-oxo-5-(2,3,5,6tetrafluoro-phenoxy)-pentanoic acid): a liver-targeted caspase inhibitor. J Pharmacol Exp Ther 2004; 309(2): 634-640 
108. Barreyro FJ, Holod S, Finocchietto PV, Camino AM, Aquino JB, Avagnina A, Carreras MC, Poderoso JJ, Gores GJ. The pancaspase inhibitor emricasan (IDN-6556) decreases liver injury and fibrosis in a murine model of non-alcoholic steatohepatitis. Liver Int 2015; 35(3): 953-966

109. Shiffman ML, Pockros P, McHutchison JG, Schiff ER, Morris M, Burgess G. Clinical trial: the efficacy and safety of oral PF03491390, a pancaspase inhibitor — a randomized placebocontrolled study in patients with chronic hepatitis C. Aliment
Pharmacol Ther 2010; 31(9): 969-978

110. Duke BO. The effects of drugs on Onchocerca volvulus. 3. Trials of suramin at different dosages and a comparison of the brands Antrypol, Moranyl and Naganol. Bull World Health Organ 1968; 39(2): $157-167$

111. Albulescu IC, Kovacikova K, Tas A, Snijder EJ, van Hemert MJ. Suramin inhibits Zika virus replication by interfering with virus attachment and release of infectious particles. Antiviral Res 2017; 143: $230-236$ 